\title{
Decisão por novas tecnologias em saúde: influências organizacionais e profissionais
}

\author{
Autores: Eiro, Natalia Yuri; Yu, Abraham Sin Oih
}

\section{Introdução}

A avaliação de tecnologias de saúde (ATS) tornouse parte indispensável da governança dos sistemas de saúde, estimulado pela pressão tecnológica e econômica do desenvolvimento da saúde (Trindade, 2013).

Organização Mundial da Saúde (2015) reforça que a decisão correta pela tecnologia requer um processo multidisciplinar dentro da própria instituição e entre toda a rede de saúde (pública e privada) para avaliar o prisma social, econômico, organizacional e ético.

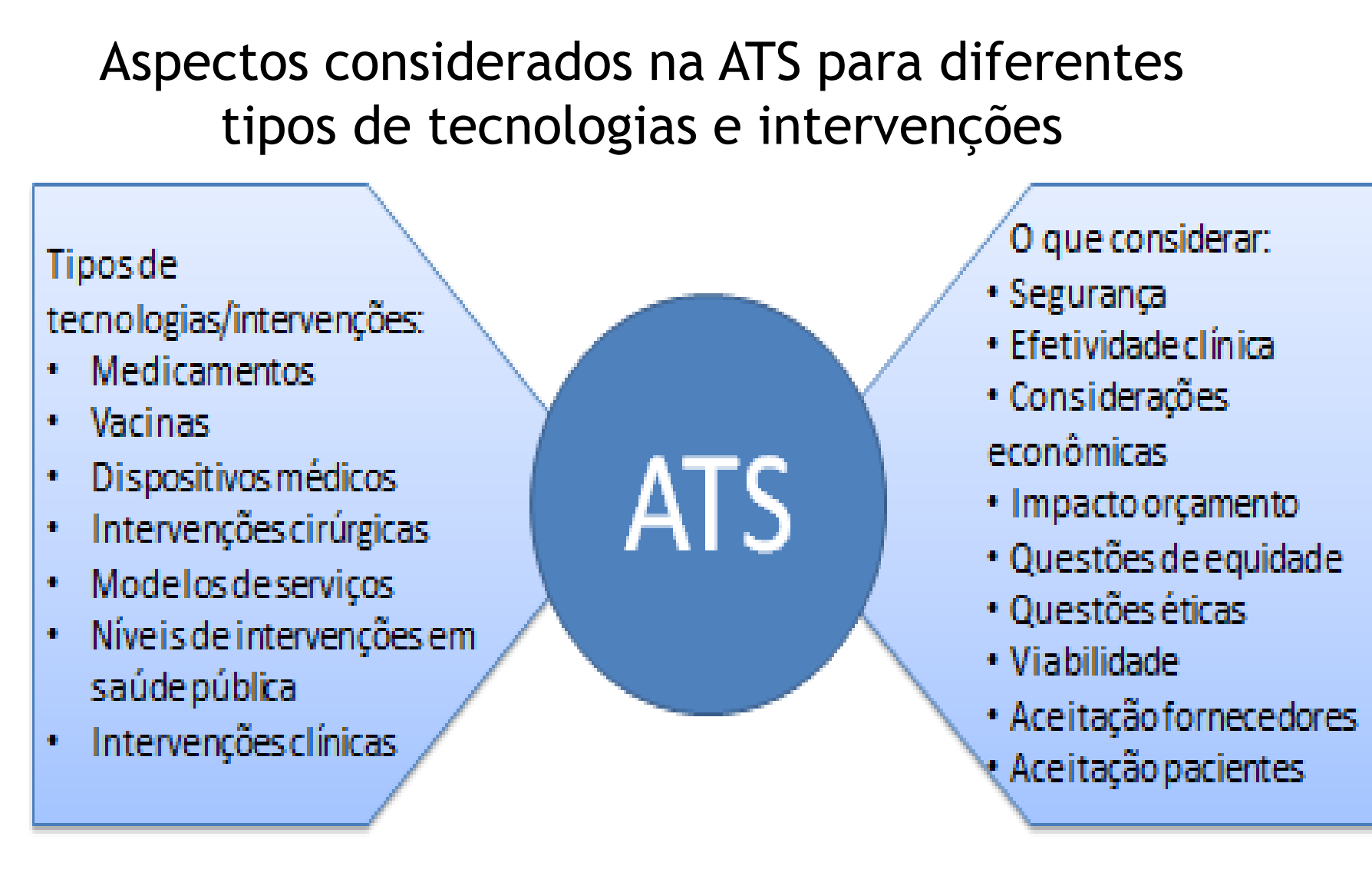

Fonte: adaptado de WHO, 2015

\section{Objetivo}

Compreender os fatores (internos/externos às organizações) não considerados nas ATSs e avaliar a influência destes no processo de aquisição de tecnologia em saúde

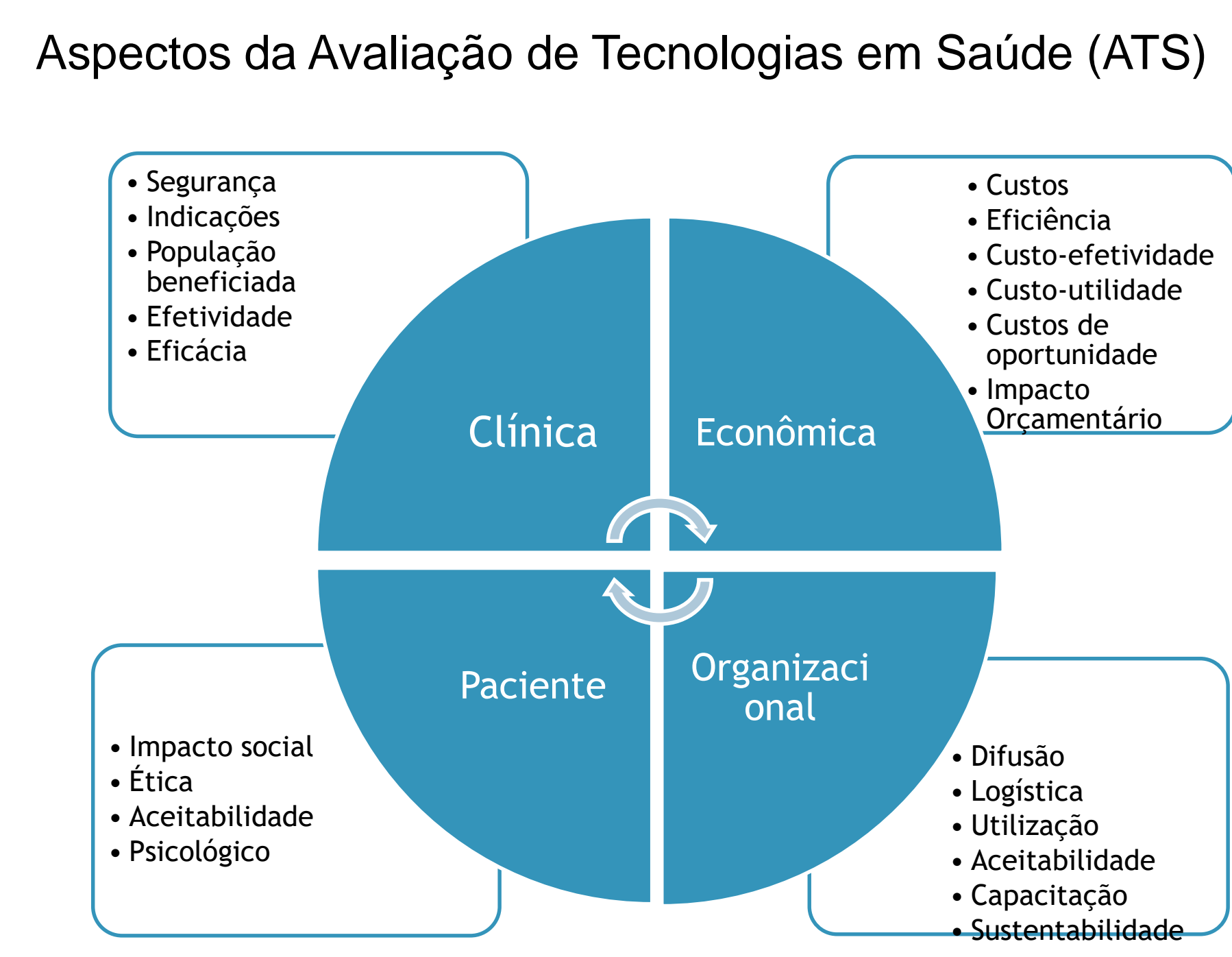

Fonte: Adaptado do documento Brasil (MS), 2016.

\section{Revisão de Literatura}

\section{Inovação}

$$
\text { Aquisição de Inovação }
$$

Processo Decisório

\section{Aquisição de Tecnologia em Saúde}

\section{Justificativa do Estudo}

1. Desafios de alocação dos recursos disponíveis para maximizar a saúde

2. Barreiras e contribuições da ATS entre a rede dos sistemas de saúde: tomada de decisão $x$ tecnologia

3. Identificação de premissas aplicadas nos serviços privados

4. Racionalidade limitada: organização como decisora unitária e centralizada

5. Foco ATS em tecnologias isoladas - carteira de tecnologias

\section{Metodologia de Pesquisa}

1. Revisão da literatura para construir um modelo teórico direcionador da coleta de dados e apoiar a análise dos dados;

2. Pesquisa qualitativa e indutiva;

3. Estratégia de teorização Sintética segundo Langley (1999)

4. Estudo de dois casos por meio de entrevistas com influenciadores no processo de tomada de decisão na aquisição de tecnologias em saúde.

\section{Coleta de Dados}

\begin{tabular}{|c|c|c|}
\hline & Caso 1 & Caso 2 \\
\hline Instituição & Privada & Pública \\
\hline Tipo & $\begin{array}{c}\text { Medicina } \\
\text { Diagnóstica }\end{array}$ & $\begin{array}{c}\text { Hospital } \\
\text { Cardiológico }\end{array}$ \\
\hline Formação & Engenheiro & Médico \\
\hline Cargo & Diretor de Inovação & $\begin{array}{c}\text { Coordenador } \\
\text { Departamento de } \\
\text { ATS }\end{array}$ \\
\hline $\begin{array}{l}\text { Tempo de } \\
\text { cargo }\end{array}$ & 3,5 anos & 19 anos \\
\hline Caso & $\begin{array}{l}\text { Compra de um } \\
\text { sequenciador } \\
\text { genético }\end{array}$ & $\begin{array}{c}\text { Oferta de } \\
\text { imunossupressores } \\
\text { a pacientes } \\
\text { transplantados }\end{array}$ \\
\hline
\end{tabular}

\section{Conclusões}

1.As decisões não consideram o sistema como um todo. As organizações comportam-se como decisoras centrais e únicas na aquisição de novas tecnologias

2.As organizações e/ou profissionais não utilizam a racionalidade ao decidir por uma nova tecnologia e existem interesses políticos, econômicos, sociais e pessoais durante o processo de aquisição de uma tecnologia que interferem na escolha desta

3.ATS é mais normativa que prescritiva, pois não considera as limitações de capacidade humana e as complexidades dentro da cadeia de valor

\section{Referências Bibliográficas}

1.WHO (World Health Organization). (2015). Global Survey on Health Technology Assessment by National Authorities. Main findings. WHO Library Cataloguing-in-Publicatin

2.Langley, A. (1999). Strategies for theorizing process data. Academy of Management review, 24(4), 691 71

3.Trindade, E. (2008). Adoption of new technologies by health services: the challenge of analyzing relevant factors. Cadernos de saude pública, 24(5), 951-964. 